\title{
Maternal Outcome of Prolonged Pregnancy
}

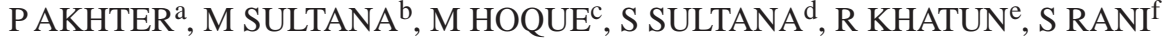

\section{Summary:}

The probability of a pregnancy terminating in a full-term, healthy live birth is a powerful indicator of the health status of its women, and of the quality of health care available to them during pregnancy and birth. The present study conducted to find out the maternal outcome of prolonged pregnancy. This study carried out in the department of obstetrics, Sir Salimullah Medical College and Mitford Hospital, Dhaka, between the period of February 2003 and December 2003. Patients admitted in labour ward having the history of post dates but not in labour and some were admitted during first stage of labour. Patients who were sure about their Last Menstrual Period (LMP) and those patients who had regular menstrual cycle were included in the study. Total 139 respondents were included in the study. Among them 114 (82.01\%) were in the age group of 18 to 29 years and 25 (17.99\%) were in the age group of $\geq 30$ years. Among the respondents 67 (48.2\%) were primi gravida and 72 (51.8\%) were multi gravida. Among the respondents 92 (66.2\%) were in the 1st stage of labour, 7 (5.0\%) were in the

\section{Introduction:}

Pregnancy is a time when women's health is placed at risk; however, health professionals providing prenatal care can reduce that risk by monitoring women's health regularly and offering preventive services ${ }^{1}$. Every year more than 200 million women become pregnant ${ }^{2}$. Most pregnancies of healthy mothers end with the birth of a live baby. But, in many cases, childbirth is not the joyous

a. Dr Parul Akhter, Junior Consultant (Gynae), 200 Beded Hospital, Narayanganj

b. Dr. Masuda Sultana, Junior Consultant (Gynae), UHC, Meghna, Comilla.

c. Dr. Mahbuba Hoque, Junior Consultant (Gynae), Sadar Hospital, Narsingdi.

d. Dr. Sharmin Sultata, Gynae outdoor. 200 Beded Hospital, Narayanganj

e. Dr. Mst. Rahima Khatun, Junior Consultant (Gynae), Sadar Hospital, Satkhira.

f. Dr. Seema Rani Dabee. Junior Consultant (Gynae), 20 Beded Hospital, Aminbazar, Savar, Dhaka.

Address of Correspondence: Dr. Parul Akhter, Junior Consultant (Gynae), 200 Beded Hospital, Narayanganj. Mobile: 01711648370, E-mail: drparulakhter@yahoo.com

Received: 28 February, 2013

Accepted: 13 January, 2014 2nd stage of labour and rest 40 (28.8\%) were not in labour. Mode of delivery of highest number of respondents was caesarian section (54.0\%) followed by normal vaginal delivery (39.7\%). Other mode of delivery were ventouse and forceps and they were $07(05.0 \%$ ) and $2(1.4 \%)$ respectively. Out of 75 respondents under gone caesarian section, indication of C/S was fetal distress in $1^{\text {st }}$ stage of labour, prolong $1^{\text {st }}$ stage with maternal distress, failed induction, cephalopelvic disproportion (CPD) and breech presentation with big baby were $32.0 \%, 25.3 \%, 24.0 \%, 16.0 \%$ and $2.7 \%$ respectively. Maternal morbidity like PPH, UTI, puerperal sepsis and wound infection were $10.0 \%, 14.40 \%, 3.60 \%$ and $5.70 \%$ respectively. In postdated pregnancy maternal morbidity is common finding. It also has more operative interference.

Key word: Postdated pregnancy; Maternal morbidity.

Abbreviation: LMP: Last Menstrual Period; CPD: Cephalopelvic disproportion; PPH: Post partum haemorrhage; UTI: Urinary tract infection.

(J Banagladesh Coll Phys Surg 2014; 32: 66-70)

event as it should be but a time of pain, fear, suffering and even death ${ }^{3,4}$. The probability of a pregnancy terminating in a full-term, healthy live birth is a powerful indicator of the health status of its women, and of the quality of health care available to them during pregnancy and birth. Improvement of pregnancy outcome is thus an important area of action for those concerned with the improvement of women's health ${ }^{5}$. Although maternal mortality is a significant global health issue, achievements in mortality decline to date have been inadequate ${ }^{6}$. During the last decade the high number of maternal deaths has caused growing public concern. Ninety nine per cent of the deaths occur in developing countries and various strategies have been promoted to reduce maternal mortality ${ }^{7,8}$. South Asia accounts for half of the world's annual maternal deaths, although it contributes only $29 \%$ of the deliveries in the world. Nearly three and half million births occur in Bangladesh every year and most of the deliveries are conducted at home by untrained persons ${ }^{9}$. In the late 1980s, one out of every 33 women in Bangladesh was estimated to have died of such complications, compared with nearly one out of 10,000 women in northern Europe. In 1987, the 
international Safe Motherhood Initiative was launched to address this problem. Unfortunately, progress has been slow, partly because of a lack of consensus on how best to reduce maternal deaths ${ }^{10}$.

The timely onset of labor and birth is an important determinant of perinatal outcome ${ }^{11}$. The World Health Organization defines a post-term pregnancy as one that has extended to or beyond 42 weeks (294 days) of gestation. Resources and maternal wishes need to be considered when managing a prolonged pregnancy ${ }^{12,13,14,15,16}$. Prolonged pregnancy is associated with an increased risk of fetal and maternal complications $^{11,15}$. The cause of prolonged pregnancy is not clear and may represent simple etiological variation. Post-term pregnancy is more common in primigravid women and a previous prolonged pregnancy gives a relative risk of 2.2 for subsequent pregnancies to be prolonged ${ }^{13}$. In most developed countries, prolonged pregnancy is now managed by planned delivery ${ }^{17}$. It is recognized as a high-risk problem faced by obstetricians. Perinatal morbidity and mortality are increased significantly and, for that reason, most obstetric units offer routine induction of labour between 41 and 42 weeks of gestation to minimize the adverse perinatal risks ${ }^{13}$, 14,16. Most women with a previous caesarean section have repeat caesarean delivery if the pregnancy becomes prolonged, as induction is associated with an increased risk of uterine rupture ${ }^{17}$.

\section{Methodology:}

The objective of the present study was to determine the maternal outcome of prolonged pregnancy. This study carried out in the department of obstetrics, Sir Salimullah Medical College and Mitford, Hospital, Dhaka, between the period of February 2003 and December 2003. During this period, patients admitted in labour ward were taken for this study. Patients were admitted in labour ward having the history of post dates but not in labour and some were admitted during first stage of labour. Patients who were sure about their L.M.P and those patients who had regular menstrual cycle were included in the study. Patients who were unable to give accurate history of their L.M.P Patients who had infrequent menstruation prior to existing pregnancy, Patients of other high risk groups e.g. PET, Ecclampsia, Heart disease, Diabetics, Renal disease, IUGR, Patients with systemic hypertension, Multiple Pregnancies and congenital abnormalities were excluded. Pregnancy occurring during lactational amenorrhoea, pregnancy with venereal diseases and pregnancy with blood group incompatibility were also excluded from the study.

\section{Results:}

Total 139 respondents were included in the study. Among them 114 (82.01\%) were in the age group of 18 to 29 years and 25 (17.99\%) were in the age group of e"30 years. Duration of pregnancy of 80 (57.6\%) was 41 weeks, 39 (28.0\%) was 42 weeks, 17 (12.2\%) was 43 weeks and rest 3 (2.2\%) was 44 weeks. Among the respondents 67 (48.2\%) were primi gravida and 72 (51.8\%) were multi gravida. Clinically ninety nine (71.2\%) respondents presented with adequate liqour amnii and 40 (28.8\%) were presented with scanty liqour amnii. Ultrasonographically 40 (56.3\%) respondents presented with adequate liqour amnii, 15 (21.1\%) presented with inadequate liqour amnii and 16 (22.6\%) were presented with scanty liqour amnii. Among the respondents 92 (66.2\%) were in the 1 st of labour, 7 (5.0\%) were in the 2nd stage of labour and rest 40 (28.8\%) were not in labour. Among the respondents not in labour, twenty four (60.0\%) had favourable cervix and 16 (40.0\%) had unfavourable cervix. Sweeping, sweeping + ARM and prostaglandin were the methods of induction among the women not in labour and they were 8 (20.0\%), $16(40.0 \%)$ and $16(40.0 \%)$ respectively. Mode of delivery of highest number of respondents was caesarian section (54.0\%) followed by normal vaginal delivery (39.7\%). Other modes of delivery were ventouse and forceps and they were 07(05.0\%) and $2(1.4 \%)$ respectively. Out of 75 respondents under gone caesarian section, indication of $\mathrm{C} / \mathrm{S}$ was fetal distress in $1^{\text {st }}$ stage of labour, prolong $1^{\text {st }}$ stage with maternal distress, failed induction, cephalopelvic disproportion (CPD) and breech presentation with big baby were $32.0 \%$, 25.3\%, 24.0\%, 16.0\% and 2.7\% respectively. Maternal morbidity PPH, UTI, puerperal sepsis and wound infection were 10.0\%, $14.40 \%, 3.60 \%$ and $5.70 \%$ respectively. 
Table-I

\begin{tabular}{|c|c|c|}
\hline Characteristics & Frequency & Percent \\
\hline \multicolumn{3}{|l|}{$\overline{\text { Age (years) }}$} \\
\hline $18-29$ & 114 & 82.01 \\
\hline$\geq 30$ & 025 & 17.99 \\
\hline \multicolumn{3}{|c|}{ Duration of pregnancy (weeks) } \\
\hline 41 & 80 & 57.6 \\
\hline 42 & 39 & 28.0 \\
\hline 43 & 17 & 12.2 \\
\hline 44 & 03 & 02.2 \\
\hline \multicolumn{3}{|l|}{ Gravida } \\
\hline Primi gravida & 67 & 48.20 \\
\hline Multi gravida & 72 & 51.80 \\
\hline \multicolumn{3}{|c|}{ Amount of liqour amnii (Clinical) } \\
\hline Adequate & 99 & 71.20 \\
\hline Scanty & 40 & 28.80 \\
\hline \multicolumn{3}{|c|}{ Amount of liqour amnii (USG) (n=91) } \\
\hline Adequate & 40 & 56.3 \\
\hline Inadequate & 15 & 21.1 \\
\hline Scanty & 16 & 22.6 \\
\hline \multicolumn{3}{|l|}{ Stages of labour } \\
\hline 1st stage & 92 & 66.2 \\
\hline 2nd stage & 07 & 05.0 \\
\hline Not in labour & 40 & 28.8 \\
\hline \multicolumn{3}{|c|}{ Condition of cervix among the women not in labour $(n=40)$} \\
\hline Favourable & 24 & 60.0 \\
\hline Not favourable & 16 & 40.0 \\
\hline \multicolumn{3}{|c|}{ Methods of induction among the women not in labour $(\mathrm{n}=40)$} \\
\hline Sweeping & 08 & 20.0 \\
\hline Sweeping + ARM & 16 & 40.0 \\
\hline Prostaglandin & 16 & 40.0 \\
\hline
\end{tabular}

Table-II

Distribution of mode of delivery among the study group.

Frequency Percentage

Mode of delivery among cases ( $\mathrm{n}=139)$

\begin{tabular}{lll} 
NVD & 55 & 39.7 \\
Ventouse & 07 & 05.0 \\
Forceps & 02 & 01.4 \\
$\mathrm{C} / \mathrm{S}$ & 75 & 54.0 \\
Indications of cesarean section (n=75) & & \\
Fetal distress in 1 ${ }^{\text {st }}$ stage of labour & 24 & 32.0 \\
Prolong $1^{\text {st }}$ stage with maternal distress & 19 & 25.3 \\
Failed induction & 18 & 24.0 \\
Cephalopelvic disproportion (CPD) & 12 & 16.0 \\
Breech presentation with big baby & 02 & 02.7 \\
\hline
\end{tabular}

Table-III

\begin{tabular}{|c|c|c|}
\hline \multicolumn{3}{|c|}{$\begin{array}{c}\text { Distribution of maternal morbidity among } \\
\text { the study group. }\end{array}$} \\
\hline & Frequency & Percentage \\
\hline \multicolumn{3}{|c|}{ Maternal morbidity $(\mathrm{n}=139)$} \\
\hline PPH & 14 & 10.0 \\
\hline UTI & 20 & 14.4 \\
\hline Puerperal sepsis & 05 & 03.6 \\
\hline Wound infection & 08 & 05.7 \\
\hline
\end{tabular}

\section{Discussion:}

Complications of pregnancy and childbirth are the leading cause of premature death among women in developing countries ${ }^{10}$. Prolonged pregnancies are associated with both fetal and maternal complications. A variety of management practices can be utilized to mitigate the risk of these complications. Prolonged pregnancies, although less common in the era of ultrasound dating, are associated with fetal and maternal risks $^{18}$.

In the present study total 139 respondents with prolonged pregnancy were included. Among them 114 (82.01\%) were in the age group of 18 to 29 years and 25 (17.99\%) were in the age group of e"30 years. Duration of pregnancy of 80 (57.6\%) was 41 weeks, 39 (28.0\%) was 42 weeks, 17 (12.2\%) was 43 weeks and rest $3(2.2 \%)$ was 44 weeks. Among the respondents 67 (48.2\%) were primi gravida and 72 (51.8\%) were multi gravida. Clinically ninety nine $(71.2 \%)$ respondents presented with adequate liqour amnii and 40 (28.8\%) were presented with scanty liqour amnii. Ultrasonographically 40 (56.3\%) respondents presented with adequate liqour amnii, 15 (21.1\%) presented with inadequate liqour amnii and 16 (22.6\%) were presented with scanty liqour amnii.

The first decision that must be made when managing an impending post term pregnancy is whether to deliver. In certain cases the decision is straightforward. However, frequently several options can be considered when determining a course of action in the low-risk pregnancy. The certainty of gestational age, cervical examination findings, estimated fetal weight, patient preference, and past obstetric history must all be considered when mapping a course of action ${ }^{19}$. Among the respondents 92 (66.2\%) were in the 1st of labour, 7 
(5.0\%) were in the 2nd stage of labour and rest 40 (28.8\%) were not in labour. Among the respondents not in labour, twenty four (60.0\%) had favourable cervix and 16 (40.0\%) had unfavourable cervix.

Women undergoing labor induction because of prolonged pregnancy should be sufficiently informed regarding the risks of a cesarean section or a vacuum extraction ${ }^{20}$. Sweeping, sweeping + ARM and prostaglandin were the methods of induction among the women not in labour and they were 8 (20.0\%), 16 (40.0\%) and $16(40.0 \%)$ respectively. Abotalib et al. ${ }^{21}$ in a study showed that labor induction and operative delivery rates were significantly higher in prolonged pregnancies. However, there were no significant differences between the patients who were induced and those who had spontaneous labor among the prolonged pregnancies.

Prolonged pregnancy is a common indication for planned delivery ${ }^{17}$. In the present study the mode of delivery of highest number of respondents was caesarian section (54.0\%) followed by normal vaginal delivery (39.7\%). Other modes of delivery were ventouse and forceps and they were $07(05.0 \%)$ and $2(1.4 \%)$ respectively. Out of 75 respondents under gone caesarian section, indication of $\mathrm{C} / \mathrm{S}$ was fetal distress in $1^{\text {st }}$ stage of labour, prolong $1^{\text {st }}$ stage with maternal distress, failed induction, cephalopelvic disproportion (CPD) and breech presentation with big baby were $32.0 \%, 25.3 \%$, $24.0 \%, 16.0 \%$ and $2.7 \%$ respectively. Abotalib et al. ${ }^{21}$ in a study showed that operative delivery rates were significantly higher in prolonged pregnancies. Studies by Hannah et al. ${ }^{22}$, Knox et al. ${ }^{23}$ and Sanchez-Ramos et al. ${ }^{24}$ showed that elective induction of labor not only is rate of cesarean delivery not increased in women who were randomized to routine induction of labor, but also more cesarean deliveries were performed in the noninduction groups, and the most frequent indication was fetal distress ${ }^{19}$. Risk factors intrinsic to the patient, rather than labor induction itself, are the cause of excess cesarean deliveries in women with prolonged pregnancies $^{25}$.

The maternal risks of post term pregnancy are often underappreciated $^{19}$. In the present study maternal morbidity such as PPH, UTI, puerperal sepsis and wound infection were $10.0 \%, 14.40 \%, 3.60 \%$ and $5.70 \%$ respectively. In studies by Rand et al. ${ }^{26}$, Campbell et al. ${ }^{27}$, Alexander et al. ${ }^{28}$, and Treger et al. ${ }^{29}$ showed an increase in labor dystocia (9-12\% vs $2-7 \%$ at term), an increase in severe perineal injury ( $3^{\text {rd }}$ and $4^{\text {th }}$ degree perineal lacerations) related to macrosomia (3.3\% vs $2.6 \%$ at term) and operative vaginal delivery, and a doubling in the rate of cesarean delivery ( $14 \%$ vs $7 \%$ at term). Increased rate of cesarean delivery is associated with higher risks of complications such as endometritis, hemorrhage, and thromboembolic disease ${ }^{28,30}$.

\section{Conclusion:}

Rate of caesarean section in post-dated pregnancy was more than fifty percent, which is higher than the rate in term pregnancy. In the future we need to develop more effective strategies to reduce perinatal morbidity at term by selective delivery based on overall risk, not on gestational age alone.

\section{Limitation of the study:}

Because of illiteracy and lack of awareness of the patient, inaccurate LMP was a problem. There is no facility for emergency ultra sonogram in this hospital.

\section{References:}

1. Villar J and Bergsjo P. Scientific basis for the content of routine antenatal care. I. Philosophy, recent studies \& power to eliminate or alleviate adverse maternal outcomes. ActaObstetricia et Gynecologica Scandinavica 1997; 76(1): $1-14$.

2. World Health Organization (WHO). Mother-baby package: a safe motherhood planning guide. Geneva: World Health Organization, 1994 [Draft 3].

3. International Conference on Population and Development, Cairo. Programme for Action. Cairo: United Nations, 1994.

4. World Health Organization (WHO). Maternal mortality in 1995: Estimates developed by WHO, UNICEF \& UNFPA. 2001, Ref.WHO/RHR/01.9.

5. Sundari TK. Can health education improve pregnancy outcome? Report of a grassroots action education campaign. The Journal of Family Welfare 1993. 39(1):1-12.

6. Prata N, Passano P, Sreenivas A, Gerdts CE. Maternal mortality in developing countries: challenges in scaling-up priority interventions. Women’s Health 2010;6(2):311-327.

7. Berg CJ. Prenatal care in developing counties: The World Health Organization technical working group on antenatal care. Journal of the American Medical Women's Association 1995;50(5): 182-186.

8. Carroli G, Villar J, Piaggio G, Khan-Neelofur D, Gulmezoglu M, Mugford M, Lumbiganon P, Farnot U, Bersgjo P. WHO Antenatal Care Trial Research Group. WHO systematic review 
of randomised controlled trials of routine antenatal care. Lancet 2001; 357(9268): 1565-1570.

9. Islam MT, Hossain MM, Islam MA, Haque YA. Improvement of coverage and utilization of EmOC services in southwestern Bangladesh. International Journal of Gynecology and Obstetrics 2005; 91: 298-305.

10. Maine D, Akalin MZ, Chakraborty J, de Francisco A, Strong M. Why Did Maternal Mortality Decline in Matlab? Studies in Family Planning 1996; 27(4):179-187.

11. Norwitz ER. Snegovskikh VV, Caughey AB. Prolonged Pregnancy: When Should We Intervene? Clinical Obstetrics \& Gynecology 2007; 50(2): 547-557.

12. Delaney M, Roggensack A, Leduc DC, Ballermann C, Biringer A, Dontigny L. Guidelines for the Management of Pregnancy at $41+0$ to $42+0$ Weeks. J Obstet Gynaecol Can 2008; 30(9): 800-810.

13. Luckas MJM and Walkinshaw SA. Prolonged pregnancy. The Ohstetriciarz G Gynaecologist 2000;2(1): 39-41.

14. Olesen AW, Basso O, Olsen J. Risk of recurrence of prolonged pregnancy. BMJ 2003; 326: 476.

15. Olesen AW. Prolonged pregnancy: methods, causal determinants and outcome. Dan Med Bull 2004; 51:148.

16. Siozos C and Stanley KP. Prolonged pregnancy. Current Obstetrics and Gynaecology 2005; 15 (2): 73-79.

17. Bailey D. Management of prolonged pregnancy: Yesterday, today and tomorrow. O\&G Magazine 2010; 12(2): 20-21.

18. Doherty L and Norwitz ER. Prolonged pregnancy: when should we intervene? Current Opinion in Obstetrics \& Gynecology 2008; 20(6): 519-527.

19. Caughey AB and Butler JR. Postterm Pregnancy. Available from:www.emedicine.com, Last updated: 13/09/2010[Access 30/12/2010].

20. Bodner-Adler B, Bodner K, Pateisky N, Kimberger O, Chalubinski K, Mayerhofer K, Husslein P. Influence of labor induction on obstetric outcomes in patients with prolonged pregnancy: a comparison between elective labor induction and spontaneous onset of labor beyond term. Wien Klin Wochenschr 2005; 117(7-8): 287-92.

21. Abotalib ZM, Soltan MH, Chowdhury N, Adelusi B. Obstetric outcome in uncomplicated prolonged pregnancy. International Journal of Gynecology \& Obstetrics1996; 55(3): 225-230.

22. Hannah ME, Hannah WJ, Hellmann J, Hewson S, Milner R, Willan A, and the Canadian Multicenter Post-term Pregnancy Trial Group. Induction of Labor as Compared with Serial Antenatal Monitoring in Post-Term Pregnancy - A Randomized Controlled Trial. N Engl J Med 1992; 326:15871592.

23. Knox GE, Huddleston JF, Flowers CE Jr. Management of prolonged pregnancy: results of a prospective randomized trial. Am J Obstet Gynecol 1979; 134(4): 376-84.

24. Sanchez-Ramos L, Olivier F, Delke I. Labor induction versus expectant management for postterm pregnancies: a systematic review with meta-analysis. Obstet Gynecol 2003; 101(6): 1312-1318.

25. Alexander JM, MCIntire DD, Leveno KJ. Prolonged pregnancy: induction of labor and cesarean births. Obstet Gynecol. 2001; 97(6): 911-915.

26. Rand L, Robinson JN, Economy KE, et al. Post-term induction of labor revisited. Obstet Gynecol 2000; 96(5 Pt 1): 779-783.

27. Campbell MK, Ostbye T, Irgens LM. Post-term birth: risk factors and outcomes in a 10-year cohort of Norwegian births. Obstet Gynecol. 1997;89(4):543-548.

28. Alexander JM, McIntire DD, Leveno KJ. Forty weeks and beyond: pregnancy outcomes by week of gestation. Obstet Gynecol 2000;96(2):291-294.

29. Treger M, Hallak M, Silberstein T, et al. Post-term pregnancy: should induction of labor be considered before 42 weeks? J Matern Fetal Neonatal Med 2002; 11(1):50-53.

30. Eden RD, Seifert LS, Winegar A. Perinatal characteristics of uncomplicated postdate pregnancies. Obstet Gynecol 1987; 69(3 Pt 1): 296-299. 